\title{
Carrying of dead infants by Japanese macaque (Macaca fuscata) mothers
}

\author{
Yukimaru SugiYama $^{1 *}$, Hiroyuki KURITA ${ }^{2}$, Takeshi MATsui ${ }^{3}$, Satoshi Kimoto ${ }^{3}$, Tadatoshi Shimomura ${ }^{3}$ \\ ${ }^{1}$ Kyoto University, Kyoto 606-8501, Japan \\ ${ }^{2}$ Board of Education, Oita City Municipal Office, Oita 870-8504, Japan \\ ${ }^{3}$ Takasakiyama Natural Zoo, Oita 870-0802, Japan
}

Received 19 September 2008; accepted 24 January 2009

\begin{abstract}
The quantitative and demographic features of infant-corpse-carrying behavior in Japanese macaques (Macaca fuscata) at Takasakiyama, southern Japan, have been studied over 24 years. More than $91 \%$ of the dead infants that were carried by their mothers were abandoned within a week. Mothers of all age classes exhibited this behavior and neither the carrying rate (number of carriers/number of deaths) nor the duration were significantly different between young and older mothers. The sex of the infant was not a decisive factor. Nearly $80 \%$ of all cases observed involved infants that had died within 30 days of birth. The oldest infant whose corpse was observed being carried had died at 253 days. The overall carrying rate was $15 \%$ when death had occurred within 253 days and $28.7 \%$ for infants that died within 30 days of birth. Most mothers whose infants had lived for more than a month abandoned the corpse soon after death. Some females persist in exhibiting behaviors performed towards live infants but the exact reasons for this are unclear at present.
\end{abstract}

Key words: Macaca fuscata, dead-infant carrying, maternal persistence to infant body, understanding of death, stillbirth

\section{Introduction}

Even since the earliest stages of behavioral and ecological studies on wild and semi-wild (i.e. living in the wild but provided with some food on a regular basis) Japanese macaques (Macaca fuscata) in the late 1950s, the carrying of a dead infant by its mother has been recorded on an ad hoc basis by field researchers. This behavior is rarely observed in other animals because only anthropoid primates can carry the corpse of a dead infant for extended periods without using their mouth. Even prosimian primate mothers that show some form of maternal behavior to their dead infants cannot carry them for any great length of time (Nakamichi et al., 1996) because they cannot sustain the degree of manipulation required. Nevertheless, the carrying of dead infants by anthropoid primates still poses a significant locomotor hindrance.

Japanese macaque mothers sometimes persist in carrying infant corpses until they are covered with flies and completely decayed. Occasionally a corpse may be carried until it is mummified (Figure 1). The details of this phenomenon, however, the reason why, and the context within which mothers persist in doing so have never been investigated before, as this behavior is difficult to observe in terms of frequency, let alone on a continuous basis from the time of in-

\footnotetext{
* Correspondence to: Yukimaru Sugiyama, Kitabesso 23-3, Inuyama 484-0081, Japan.

E-mail: hqvg62yd@qc.commufa.jp

Published online 10 April 2009

in J-STAGE (www.jstage.jst.go.jp) DOI: 10.1537/ase.080919
}

fant death. In the absence of precise data, this behavior had previously been interpreted anthropomorphically as a reflection of maternal affinity for the infant (see Nigi, 2004). It is equally possible, however, that mothers lack a concept of death. Nevertheless, this behavior is puzzling from a biological point of view as it is a waste of energy and seems to be of no benefit to the mother.

The carrying of an infant corpse by its mother has been reported in 12 wild or semi-wild and six captive primate species (Nakamichi et al., 1996). All, however, were anecdotal observations and involved small sample sizes (Jay, 1963; Schaller, 1963; Rahman and Parthasarathy, 1969; Van LawickGoodall, 1971; Nishida, 1973; Nash, 1974; Altmann, 1980; Mori and Dunbar, 1985; Mori and Kudo, 1986; Izawa, 1987, 1992; Matsuzawa, 1997; Hrdy, 1999; Hosaka et al., 2000; Warren and Williamson, 2004; Nakagawa, 2007). Details of this seemingly maladaptive behavior have not been clarified.

As the perinatal behavior of mothers and their behavior just after an infant's death are rarely observed in wild and semi-wild populations of non-human primates, the present study aims to report the quantitative and demographic features of this behavior in semi-wild troops of Japanese macaques and to establish what factors may drive mothers in persisting to carry a corpse.

\section{Materials and Methods}

The largest troop of Japanese macaques ever recorded in the wild was first provisioned with food by humans at the foothill of Mount Takasakiyama, in southern Japan, in 1953 


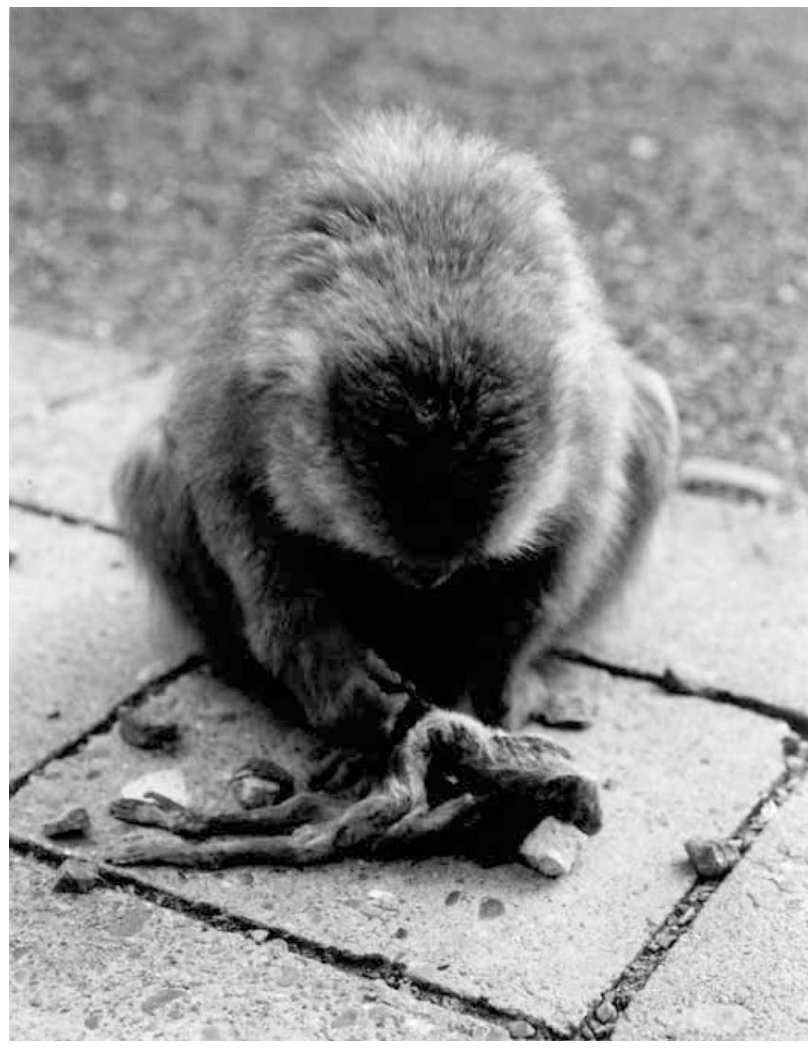

Figure 1. Carrying of a dead infant corpse which is almost mummified (photo: T. Matsui).

(Sugiyama, 1960). By 1991 the population size had increased from approximately 220 to 2000 individuals, due to increased provisioning (Sugiyama and Ohsawa, 1988; Sugiyama and Kurita, 2004). For over 50 years the troop consisted of three major troops and some smaller ones. The major troops, A, B and C, continued to come down to the provisioning area almost every day and stayed there for at least a few hours at a time (Sugiyama et al., 1995). This paper combines the demographic records of the three troops into a single population. In June 2002, Troop A deserted the original range (Kurita, unpublished) so data related to this troop were not considered beyond that date.

The Japanese macaque is a seasonal breeder (Fooden and Aimi, 2003). About 99\% of births occur between May and August at Takasakiyama (Takasakiyama Natural Zoo, 1971-2007), which roughly corresponds to the summer season in Japan. Most females first give birth between 6 and 7 years of age, occasionally 5,8 and 9 years (Sugiyama and Ohsawa, 1988). Many mothers at Takasakiyama have their last birth between 20 and 23 years, and sometimes older. At Takasakiyama, the age-specific birth rate for a female is almost the same from the first birth to about 15 years old. It then gradually decreases until the last birth (Ohsawa et al., 1977). In this paper, the Japanese macaque infant is defined as an individual from birth to about 12 months of age.

Most births in the major troops have been recorded since 1971. For 24 years (total period) from 1977 to 1993 and then from 1998 to 2004, when possible, females carrying infant corpses were recorded individually every day until they abandoned them. Infant death as well as dead infant carrying was more systematically recorded for only 9 years from 1987 to 1993 and in 2003 and 2004. During this period, females who looked pregnant were individually identified and carefully monitored on a daily basis. They were identified by their morphological characteristics but some also had facial markings. Most observation throughout the study period was by at least one of the authors. When no author was available, other park staff assisted. Data analysis is based on either the total of 24 years or on the 9 years of data, depending on the kind of demographic data discussed.

Mount Takasakiyama is semi-isolated from other natural habitats by cultivated fields and villages. The highest point, rising directly from Beppu Bay, is $628 \mathrm{~m}$ above sea level (asl) and it is surrounded by steep escarpments. The main troops travel every day from the ridge of the hill more than $500 \mathrm{~m}$ asl to the provisioning area, about $50 \mathrm{~m}$ asl. Sweet potato and wheat were given at less than $300 \mathrm{kcal}$ per day per individual during the study period (Sugiyama and Ohsawa, 1988). Animals must climb down to the provisioning area and back to the ridge of the hill in the evening in order to forage (Sugiyama, 1960). Japanese macaques eat mainly fruits, flowers and young leaves in the trees, fallen fruits and herbs on the ground, and occasionally insects (Iwamoto, 1982). For additional information on the Takasakiyama macaques, refer to Sugiyama (1960).

A newborn Japanese macaque infant weighs about $500 \mathrm{~g}$ (Shimizu, 1988), between 8 and 30 days infants weigh about $600 \mathrm{~g}$ and between 31 and 60 days infants weigh about $840 \mathrm{~g}$ (Kurita et al., 2002). Most infants attempt to stray from their mother at about one week of age but they are invariably pulled back. After two weeks, in the absence of males, the infant is allowed to start to stray and by three weeks it is allowed to wrestle with other infants. By four weeks the infant can walk steadily after its mother.

Carrying rate is defined as the number of corpse-carrying cases per total number of infant deaths.

\section{Results}

During the total 24-year period 6761 births (281.7 per year) were recorded. In the 9-year period, 2236 births were recorded (1145 males and 1091 females), of which 482 infants died (262 males and 220 females). Cases of a mother disappearing with her infant were excluded from analyses. Infant mortality (death within a year) during the 9-year period was $21.6 \%$ and the carrying rate (number of corpse-carrying cases/number of deaths within a year of birth) was $10.0 \%$.

Over the entire 24-year period, we recorded 157 cases (6.54 per year; range, 1-15; SD, 3.84) of infant corpse carrying by mothers. Of these, 145 died between June and September during the hottest, most humid period of the year. Eleven mothers carried two of their dead infants, and one mother carried three of hers. Of these, five carried corpses following consecutive deliveries. On any given day, all mothers observed carried their dead infants for the entire duration that they were in the provisioning area. 


\section{Infant longevity}

Of the 157 cases, 41 infants $(26.0 \%)$ were already dead when they were first observed at the provisioning area (longevity $=0$ day) (Figure 2). Most of these infants must have died within a few hours after birth or were stillborn.

One hundred and twenty-two infants $(77.7 \%)$ had died within 30 days of birth, while only four infants $(2.5 \%$ of all cases) lived more than 100 days, where the maximum longevity was 253 days. The mean longevity of infants whose corpses were carried was 19.9 days (range, 0-253; SD, 35.3) and the longevity of infants whose mothers carried corpses more than once over the duration of the study was 19.4 days.

During the 9-year period, 16 of 69 infants that died within a day of birth were carried by their mothers (carrying rate: $23.2 \%$ ), whereas 9 out of 10 that died 1 day after birth were carried $(90.0 \%)$. Thus, proportionately more corpses were carried when infants died 1 day after birth (Fisher's exact test, two-tailed, $P<0.001)$. Of infants who died between 1 and 30 days, 32 out of 100 were carried $(32.0 \%)$, whereas only 16 out of $369(4.3 \%)$ were carried when they died between 31 and 253 days after birth. This difference is statistically significant (Fisher's exact test, two tailed, $P<0.001$ ). Overall, then, when an infant died between 1 and 30 days it was significantly more likely to be carried than those who died on the day they were born or survived for more than 30 days (Figure 3).

\section{Duration of carrying}

Forty-five mothers (28.5\%) abandoned their infants within a day of death (Figure 4). Twenty-three mothers (14.6\%) carried them for 2 days and 39 mothers $(24.2 \%)$ did so for 3 days. Within a week of death, the dead infants of 143 mothers $(91.0 \%)$ had been abandoned.

The mean duration of carrying behavior was 3.3 days (range, 1-17; SD , 2.7). The mean carrying duration of repeat carriers was not much different at 4.04 (range, 1-16; SD,

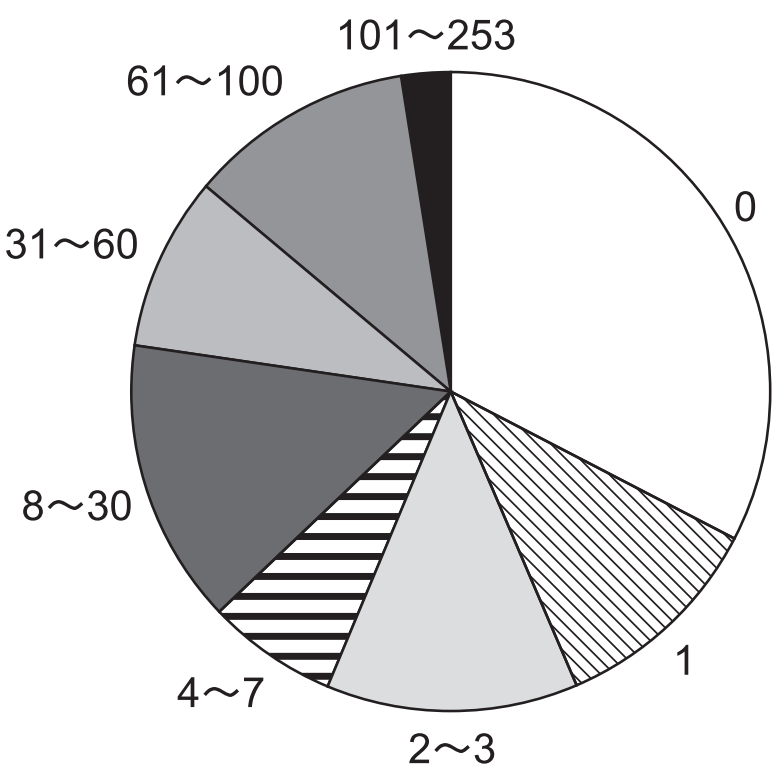

Figure 2. Comparative frequency of infant longevity for corpses which were carried by their mothers. Number shows age in days when infants died (total $=157$ cases).

3.54). The longest carrying period was 17 days. Decomposition of the corpse proceeded quickly and it was covered with flies and smelled putrid within a few days. Monkeys other than the infant's nearest sibling avoided the mother, perhaps due to the smell. Sometimes juveniles showed interest in dead infants and tried to touch and smell them, but the mothers always avoided them and concealed the corpses behind themselves. Adult females came close less frequently than usual and the frequency of social grooming clearly decreased, though quantitative data are not available.

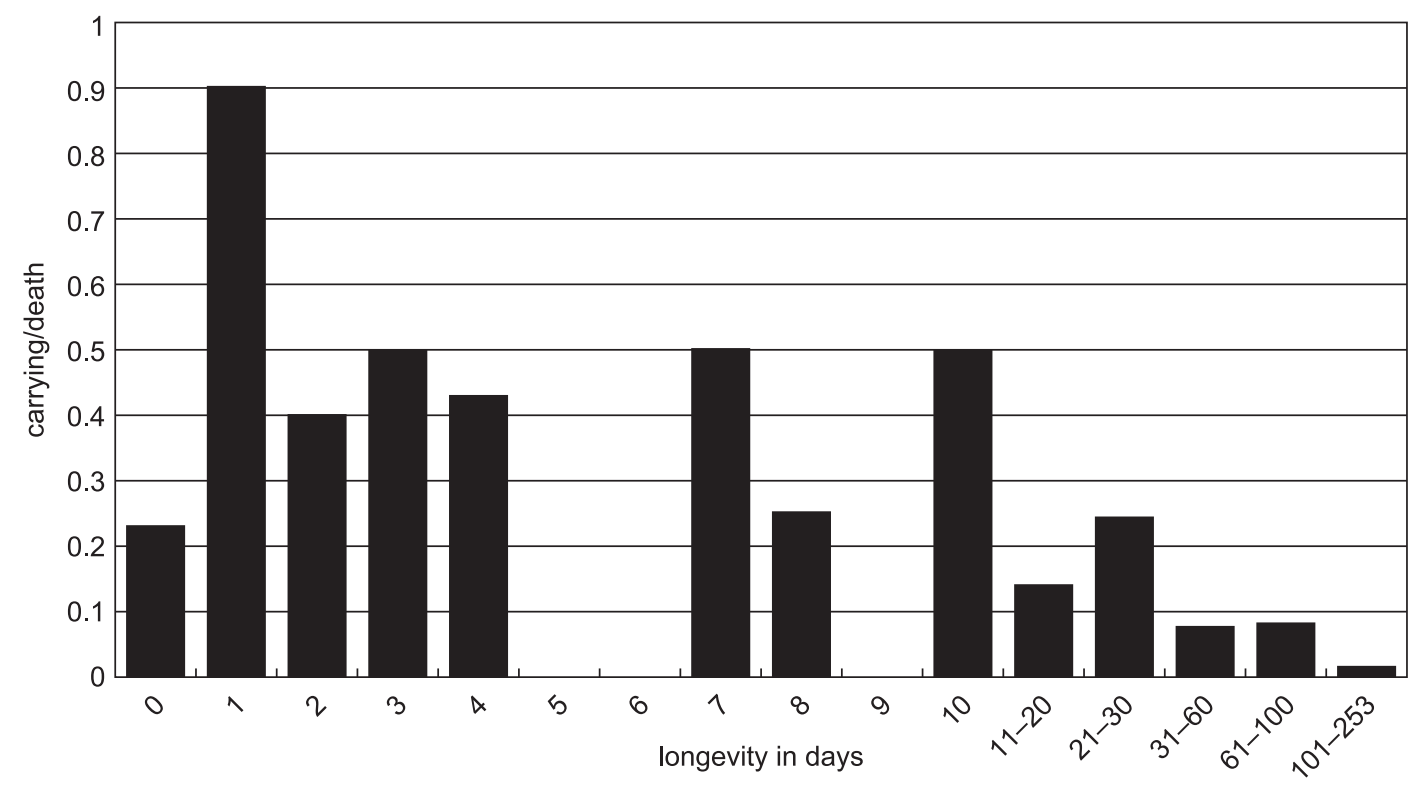

Figure 3. Carrying rate (carrying/death) of corpses relative to longevity of infant (data from 9 years of records). 


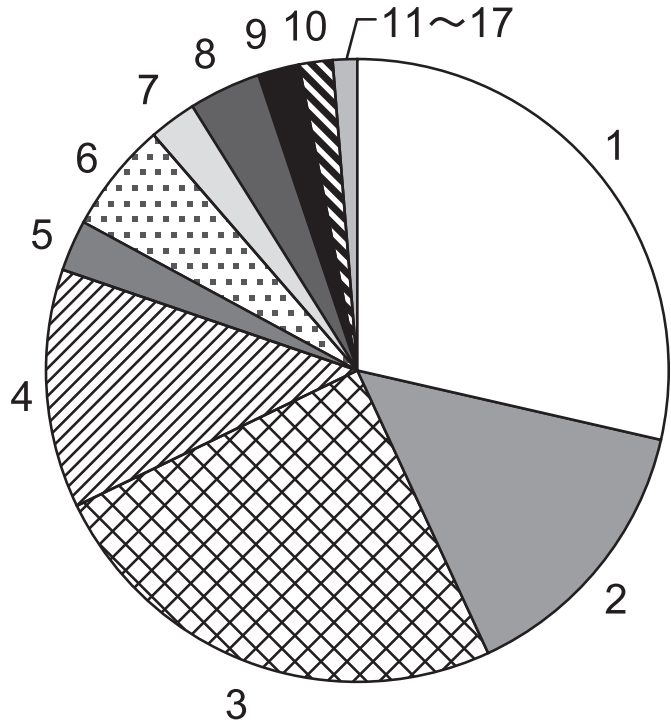

Figure 4. Comparative frequency of number of days infant corpses were carried by their mothers (total $=157$ cases).

\section{Mother's age}

The ages of 122 mothers who carried the corpse of their infants ranged from 6 to 25 years. The age of 35 mothers could not be established because they had not been followed continuously since birth. Many young mothers between 6 and 7 years of age carried their dead infant $(32.8 \%)$ (Figure 5). Most of them, perhaps all, were primiparous. The mean age of mothers was 11.4 years old, which was the same as the mean generation time (the mean delivery age of a female) at Takasakiyama (Ohsawa and Sugiyama, 1980). The average age of repeat carriers, 12.8 (range, 6-21; SD, 6.20), was not different from that of all carriers totaled.

Although mothers who carried their dead infant's bodies belonged to all age classes, the mean age of mothers who carried corpses for 8 or more days was 14.3 years (Figure 6), slightly higher than the overall mean age for corpse carrying but not significantly different (Figure 5 ). There was no difference in the carrying rate between young mothers 6-7 years old and those of 8 years or more (Fisher's exact test, two-tailed, $P=0.712$ ) and there was no significant difference between older mothers (10-25 years) and young mothers (6-7 years) in their propensity to carry a dead infant (for a duration of 8-17 days) (Fisher's exact test, two-tailed, $P=0.092$ ).

As the total number of females of each age was not recorded during the study period, the age-specific carrying rate cannot be analyzed.

\section{Sex difference}

Of the 157 infants whose corpses were carried by their mothers, the sex of 156 was confirmed as $71(45.5 \%)$ males and $85(54.5 \%)$ females. During the 9 -year study period, infant mortality within a year of birth was recorded. Infant mortality was $21.6 \%$ per year overall; $22.9 \%$ for males $(n=1145)$ and $20.2 \%$ for females $(n=1091)$; a difference that was not significant (Fisher's exact test, two tailed, $P=0.123$ ).

During the 9-year study period, 22 male corpses from 262 male infant deaths $(8.3 \%)$ and 25 of 220 female corpses $(11.4 \%)$ were confirmed as carried by their mothers. This slight sex difference in carrying rate was not statistically significant (Fisher's exact test, two tailed, $P=0.225$ ).

\section{Discussion}

The carrying of a dead infant by its mother has been observed in some provisioned or habituated troops of non-human primates. Due to the scarcity of detailed and systematic observations, this behavior was sometimes interpreted as maternal affection stimulating mothers to continue to carry their infant until mummification of the corpse (e.g. Kawai, 1964). Alternatively, this behavior can also possible be interpreted that as the mothers not understanding or having a concept of death.

The present study revealed that the carrying of infant corpses by Japanese macaque mothers occurs rather frequently. Indeed, $15.0 \%$ of infants who died within 253 days of birth were carried by their mother; 253 days being the maximum longevity of a Takasakiyama infant for which the corpse was recorded to be carried. For infants who died

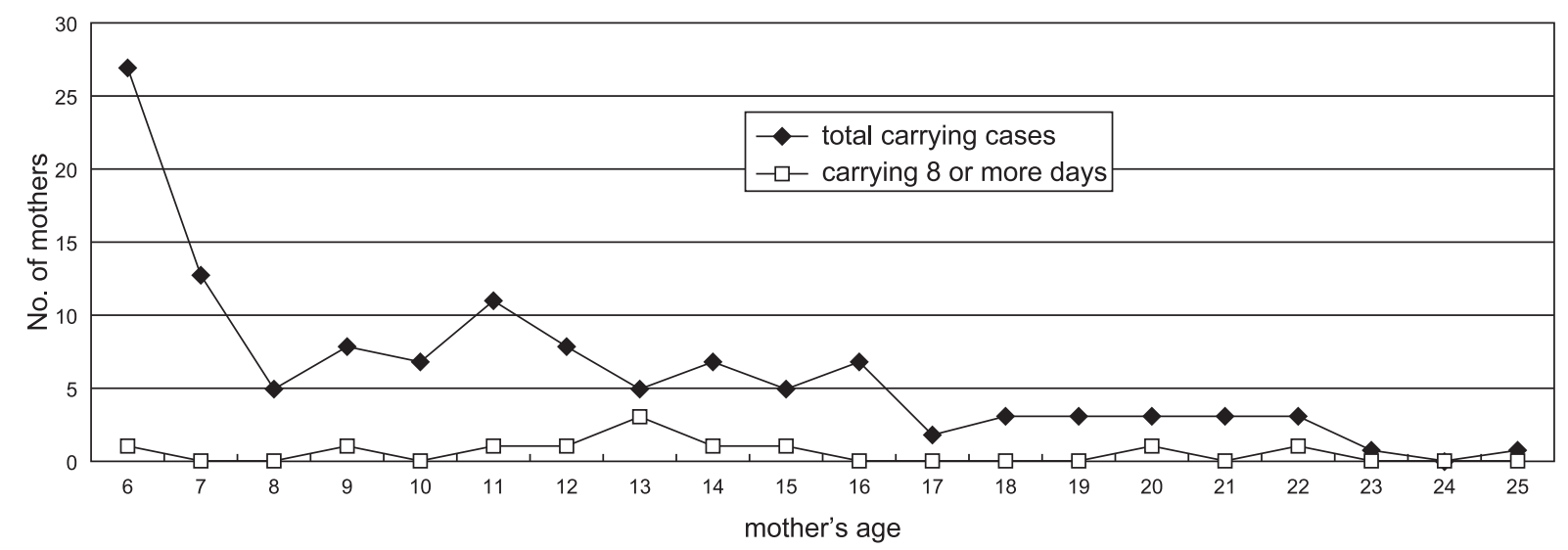

Figure 5. Relationship between mothers' age and dead-infant carrying (total $=120$ mothers). 


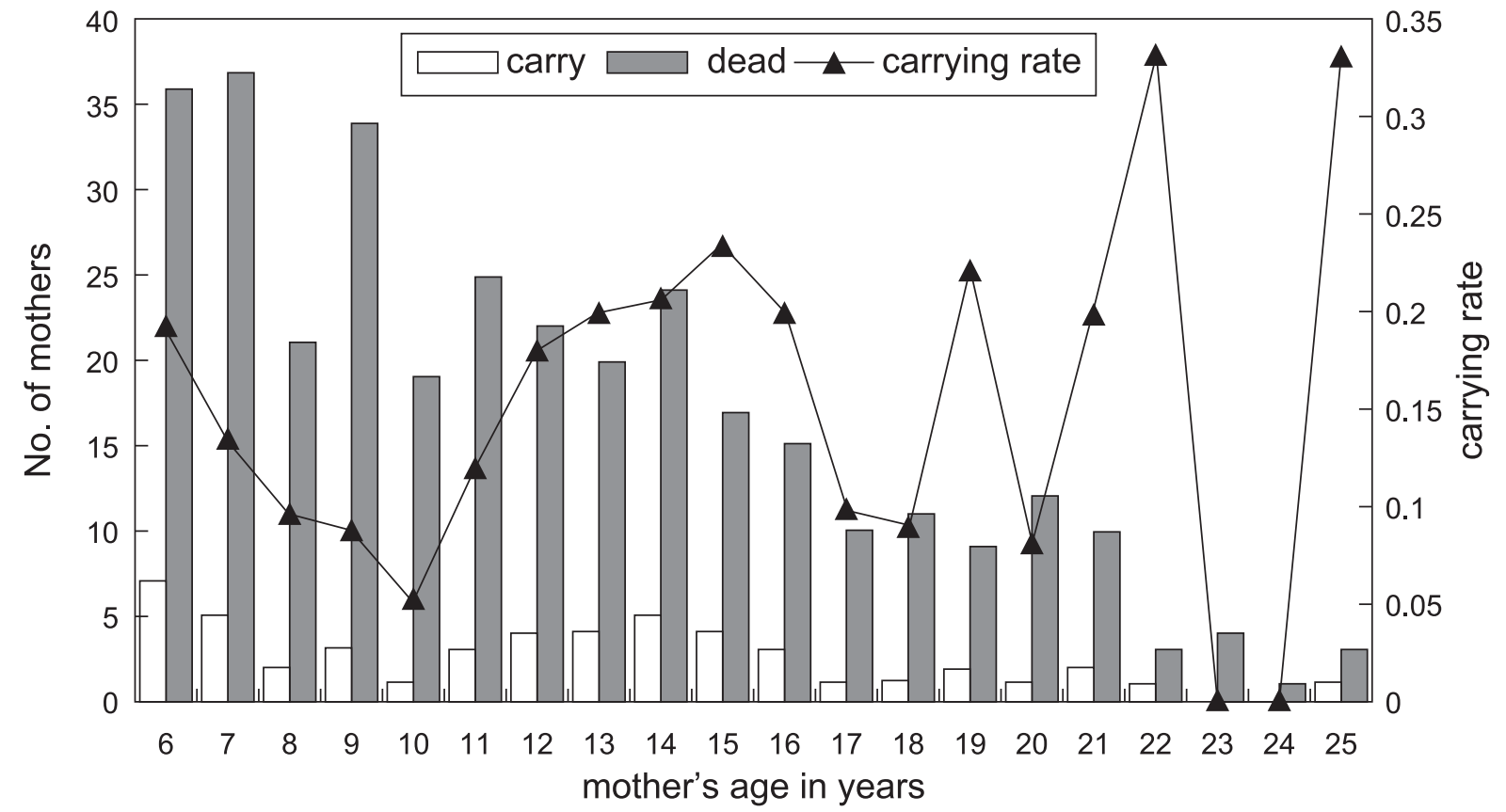

Figure 6. Infant death and the carrying rate of dead infants compared with mothers' age (data from 9 years of records).

within 30 days of birth, the carrying rate was $28.7 \%$.

Considering that many mothers were already carrying the corpse of their infant when they were first noticed, it is possible that some mothers carried stillborn infants, though this cannot be confirmed because the exact moment of delivery itself was seldom observed.

We know that a mother stands quadrupedally and bends over at the moment of delivery, so she is able to hold the head of her infant with one hand and pull it up to her breast even if the infant is stillborn. A living baby soon clings to its mothers' breast on its own and the mother only pushes it up using her hand. The carrying of a stillborn infant can be interpreted as the mother continuing her natural behavior after delivery.

The daily traveling distance of provisioned monkeys may be shorter than that of wild ones because they reliably receive preferred foods at a fixed and known feeding location. However, macaques at Takasakiyama have to vertically traverse a steep hill, about $500-600 \mathrm{~m}$ in elevation, every day (Sugiyama, 1960). The carrying of an infant corpse always occupies the mother's hand during travel and encumbers her when she is walking and feeding. Foraging with a corpse in hand must be a difficult task even for the provisioned macaques. This factor may accelerate maternal abandonment of corpses.

Most corpses were carried during the hot and/or muggy season when they decomposed rapidly, smelt bad and attracted many flies; most mothers abandoned their infants within a few days. Although we cannot compare the duration of carrying between hot and cold seasons, since only two infants died during cool and cold seasons, this seasonal factor may also have accelerated maternal abandonment of dead infants.

For wild and semi-wild monkeys, the carrying of a dead infant seems contrary to the principle of energy conservation in animals and may explain why 'maternal affinity' to an infant has been used to account for this behavior in the past (e.g. Kawai, 1964).

Given that the carrying rate of young and older, more experienced mothers was not different and that mothers who carried the dead body of their infant during consecutive births did not differ in any obvious manner from the overall tendencies observed, we do not believe that this behavior is learned.

Many infants died within 30 days and death during this earlier stage of development resulted in a carrying rate that was significantly higher than observed in those who survived longer. In particular, when infants lived more than a day but died within several days, they were significantly more likely to be carried than if they died soon after birth or lived longer. Around this age, infants cling to their mothers' breast, where they suckle continuously, and they have not yet begun to actively run and follow their mothers. When infants died after they had begun to actively run and follow their mothers by themselves, most mothers immediately or soon after abandoned their corpses. These characteristics suggest that persistence to an infant at a certain stage of dependency reinforces a mother in carrying it, even if it is immobilized and no longer living.

Hrdy (1999) claims that mothers who carry their dead infants do so not because they cannot tell the difference between the cold corpse and a live infant, but because occasionally, infants who seem dead actually wake up from a state of suspended animation. Her hypothesis may partly explain this phenomenon but, if it is true, we cannot understand why most mothers do not carry dead infants who lived for more than 30 days. Furthermore, we cannot understand why some mothers persist in carrying a corpse for more than one 
week when it is in such a bad state of decomposition.

The cumulative maternal investment in an infant that lives longer is much greater, so maternal persistency is expected to be stronger for older infants (more than one month old) than for an infant that dies a few days after birth. Given this, we would expect that maternal persistency for the infant would grow and develop, but in more than half of the carrying cases observed, the infant had died within 3 days and most within one month of birth.

A mother's proximity rate to her infant gradually decreases, particularly once the infant has passed its first developmental stage at about one month. The fact that most corpse carrying was limited to death occurring within one month means that mothers tend to continue to have the same behavior toward their infant as they did when it was alive.

The greater weight of older infants may impede mothers from persisting in corpse-carrying behavior; however, this may be a secondary consideration.

Most episodes of corpse carrying by mothers in other nonhuman primate species are anecdotal and most mothers abandon their dead ifants within several days, even in captivity (Nakamichi et al., 1996). Matsuzawa (1997) recorded a case of wild chimpanzees at Bossou, Guinea, West Africa where a 2.5-year-old juvenile died and its mother carried its carcass for 27 days. This is the oldest known dead offspring to have been carried by its mother. Instead of decomposing, it was almost mummified, as the season was very dry and hot.

A chimpanzee of 2.5 years can run on the ground and up trees for short distances but always rides on its mother's back or clings to her breast when they travel, and it continues to suckle. Although this episode may be a rare case of corpse carrying by a chimpanzee mother, such carrying may occasionally last longer (Hosaka et al., 2000) than for the Japanese macaques of Takasakiyama. As the developmental stage of this juvenile at the time of death (Van LawickGoodall, 1968) was higher than that of most Japanese macaque infants recorded in this study, the difference in carrying duration may reflect a difference in maternal persistency between monkeys and apes.

It is possible that maternal persistency to an infant's body is basically innate and reflects the origin of maternal affinity in humans, although we found no evidence for whether mothers understood that their infants were dead. Further detailed observations will be required to analyze the exact reasons for this curious behavior.

\section{Acknowledgments}

We are grateful to the managers and staff of the Takasakiyama Natural Zoo for allowing us to use daily and yearly records on the semi-wild macaques of this study. Jun Yasuda allowed us to use his unpublished data. Lafaye B. Elsom and Vanessa Hayes kindly revised our English manuscript. Our special thanks are due to Tatyana Humle and three anonymous reviewers for their valuable comments and revisions on the earlier draft. This research conforms to the rules and regulations set out by Kyoto University, Primate Research Institute's Guidelines for research on primates in captivity and the wild.

\section{References}

Altmann J. (1980) Baboon Mothers and Infants. Harvard University Press, Cambridge, MA.

Fooden J. and Aimi M. (2003) Birth-season variation in Japanese macaques, Macaca fuscata. Primates, 44: 109-117.

Hosaka K., Matsumoto-Oda A., Huffman M.A., and Kawanaka K. (2000) Reactions to dead bodies of conspecifics by wild chimpanzees in the Mahale Mountains, Tanzania. Primate Research, 16: 1-15 (in Japanese with English summary).

Hrdy S.B. (1999) Mother Nature: A History of Mothers, Infants and Natural Selection. Pantheon Books, New York.

Iwamoto T. (1982) Food and nutritional condition of free ranging Japanese monkeys on Koshima Islet during winter. Primates, 23: $153-170$.

Izawa K. (1987) The ecological study of wild Japanese monkeys living in Kinkazan, Miyagi prefecture: some discussions on the infant returned to the wild. Bulletin of Miyagi University of Education, 22: 27-49 (in Japanese with English summary).

Izawa K. (1992) Social changes within a group of wild blackcapped capuchins (Cebus paella), 3. Field Studies of New World Monkeys, La Macarena, Colombia, 7: 9-14.

Jay P. (1963) Mother-infant relationships in langurs. In: Rheingold HL. (ed.), Maternal Behavior in Mammals. John Wiley \& Sons, New York, pp. 282-304.

Kawai M. (1964) Ecology of Japanese Monkeys. Kawade-syobo, Tokyo (in Japanese).

Kurita H., Shimomura T., and Fujita T. (2002) Temporal variation in Japanese macaque body mass. International Journal of Primatology, 23: 411-428.

Matsuzawa T. (1997) The death of an infant chimpanzee at Bossou, Guinea. Pan Africa News, 4: 4-6.

Mori U. and Dunbar R.I.M. (1985) Changes in the reproductive condition of female gelada baboons following the takeover of one-male units. Zeitschrift für Tierpsychologie, 67: 215-224.

Mori U. and Kudo H. (1986) Social Development and Social Relationships of Female Japanese Monkeys. Tokai University Press, Tokyo (in Japanese).

Nakagawa N. (2007) The Running Monkeys in Savanna: Ecology and Society of Patas monkeys. Kyoto University Press, Kyoto (in Japanese).

Nakamichi M., Koyama N., and Jolly A. (1996) Maternal responses to dead and dying infants in wild troops of ringtailed lemurs at the Berenty Reserve, Madagascar. International Journal of Primatology, 17: 505-523.

Nash L.T. (1974) Parturition in a feral baboon (Papio anubis). Primates, 15: 279-285.

Nigi H. (2004) Male, Female, Men and Women: Life and Sex of Monkeys and Humans. Kodomonomirai-sha, Tokyo (in Japanese).

Nishida T. (1973) Children of Comforter: Research on the Social Organization of Chimpanzees. Chikuma-syobo, Tokyo (in Japanese).

Ohsawa H. and Sugiyama Y. (1980) A demographic model for the Takasakiyama troops of Japanese monkeys and its application to natural troops. In: Sugiyama Y. (ed.), Demographic Studies on the Society of Wild Japanese Monkeys. KUPRI, Inuyama, pp. 5-18 (in Japanese with English summary).

Ohsawa H., Sugiyama Y., and Nishimura A. (1977) Population dynamics of Japanese macaques at Takasakiyama traced by individual recognition. In: Sugiyama Y. (ed.), Research Report on the Japanese Macaques at Takasakiyama, 19711976. Oita Municipal Office, Oita, pp. 19-36 (in Japanese).

Rahman H. and Parthasarathy M.D. (1969) Studies on the social behaviour of bonnet monkeys. Primates, 10: 149-162.

Schaller G.B. (1963) The Mountain Gorilla. University of Chicago Press, Chicago.

Shimizu K. (1988) Ultrasonic assessment of pregnancy and fetal development in three species of macaque monkeys. Journal of Medical Primatology, 17: 247-256. 
Sugiyama Y. (1960) On the division of a natural troop of Japanese monkeys at Takasakiyama. Primates, 2: 109-148.

Sugiyama Y. and Kurita H. (2004) Fifty years of artificial feeding for a macaque population at Takasakiyama. Folia Primatologica, 75 (supplement 1): 343

Sugiyama Y. and Ohsawa H. (1988) Population dynamics and management of baited Japanese monkeys at Takasakiyama. Primate Research, 4: 33-43 (in Japanese with English summary).

Sugiyama Y., Iwamoto T., and Ono Y. (1995) Population control of artificially provisioned Japanese monkeys. Primate
Research, 11: 197-207 (in Japanese with English summary). Takasakiyama Natural Zoo (1971-2007) Annual Reports of Population Census of Monkeys at Takasakiyama. Oita City.

Van Lawick-Goodall J. (1968) The behaviour of free-living chimpanzees in the Gombe Stream Reserve. Animal Behaviour Monograph, 1: 161-311.

Van Lawick-Goodall J. (1971) In the Shadow of Man. Houghton Mifflin, Boston.

Warren Y. and Williamson E.A. (2004) Transport of dead infant mountain gorillas by mothers and unrelated females. Zoo Biology, 23: 375-378. 